\title{
Cognitive ability and sentience: Which aquatic animals should be protected?
}

\author{
D. M. Broom* \\ Centre for Animal Welfare and Anthrozoology, Department of Veterinary Medicine, University of Cambridge, \\ Madingley Road, Cambridge CB3 0ES, UK
}

\begin{abstract}
It is of scientific and practical interest to consider the levels of cognitive ability in animals, which animals are sentient, which animals have feelings such as pain and which animals should be protected. A sentient being is one that has some ability to evaluate the actions of others in relation to itself and third parties, to remember some of its own actions and their consequences, to assess risk, to have some feelings and to have some degree of awareness. These abilities can be taken into account when evaluating welfare. There is evidence from some species of fish, cephalopods and decapod crustaceans of substantial perceptual ability, pain and adrenal systems, emotional responses, long- and short-term memory, complex cognition, individual differences, deception, tool use, and social learning. The case for protecting these animals would appear to be substantial. A range of causes of poor welfare in farmed aquatic animals is summarised.
\end{abstract}

KEY WORDS: Animal protection $\cdot$ Animal welfare $\cdot$ Sentience $\cdot$ Cognitive ability $\cdot$ Feelings $\cdot$ Fish Cephalopoda $\cdot$ Decapoda

Resale or republication not permitted without written consent of the publisher

\section{HUMAN OBLIGATIONS AND THE QUALITIES OF ANIMALS TO CONSIDER WHEN DECIDING WHETHER TO PROTECT THEM}

Many living organisms are used by humans, and many others are affected by human activities. The issue of the grounds on which we should be concerned about them, and which of them we should protect in some way, is also considered by D. M. Broom \& K. E. Littin (unpubl.). Every living organism is likely to be the subject of more reverence than an inanimate object because living organisms are qualitatively different from inanimate objects in complexity, potential and aesthetic quality. This can affect decisions about whether to kill the organism and whether to conserve such organisms. As a consequence of their ability to respond and behave, we consider that we have more obligations to an animal than to a micro-organism or plant. We feel concerned about their welfare, especially in the case of the more complex animals (Broom 2003). Which kinds of animal deserve such consideration?
Concern for animal welfare is increasing rapidly and is a significant factor affecting whether or not animal products are bought. If a product is perceived to have adverse effects on human health, animal welfare or the environment, sales can slump dramatically (Bennett 1994). The more valuable the product, the richer the consumers and the more likely they are to decide not to buy a product on grounds such as the poor welfare of fish (Broom 1994). The fish-farming industry cannot afford to ignore fish welfare when bad publicity about it could affect sales greatly (Broom 1999).

Our knowledge of the functioning of the brain and nervous system and of animal welfare has advanced rapidly in recent years (Broom \& Johnson 2000, Broom \& Zanella 2004). New knowledge has tended to show that the abilities and functioning of non-human animals are more complex than had previously been assumed, so it is my opinion that some re-appraisal of the threshold levels for protection is needed. Proposals for change have been made by the EFSA Scientific Panel on Animal Health and Welfare (2005). 


\section{WHY DO WE PROTECT SOME ANIMALS?}

For some of the people responsible for deciding which animals deserve protection, so that poor welfare is prevented, the key issue is whether or not those animals are useful. Other arguments about which animals to protect have involved analogy with humans in that if the animals seem to be more like us, they are considered to be more worthy of protection. The argument advocated here and by D. M. Broom \& K. E. Littin (unpubl.) views the qualities of the animal on an absolute scale that includes known animals, but would also be relevant to unknown living beings such as those that might be found on another planet. Such arguments can be supported by scientific evidence (see below), which has increased more and more in recent years.

Evidence that can be used to decide on the animals that should be protected (from D. M. Broom \& K. E. Littin unpubl.):

- Complexity of life and behaviour

- Learning ability

- Functioning of the brain and nervous system

- Indications of pain or distress

- Studies illustrating the biological basis of suffering and other feelings such as fear and anxiety

- Indications of awareness based on observations and experimental work

Such evidence is considered in the remainder of this essay.

Some of those who have sought to compare the cognitive abilities of animals of different species have reported on total brain size or the size of some part of the brain (Jerison 1973, Hemmer 1983). However, some animal species or individuals function very well with very small brains, or with a small cerebral cortex. The brain can compensate for lack of tissue or, to some extent, for loss of tissue. Some people who have little or no cerebral cortex have great intellectual ability. There are many anomalies in relationships between ability and brain size, so no comparative conclusions can be reached except in relation to grossly aberrant individuals or within small taxonomic groups (Barton \& Dunbar 1997, Broom 2003). In contrast, studies of complexity of brain function can give much information about ability as well as about welfare (Broom \& Zanella 2004).

Where there is reference to the brain of animals in discussions of their complexity, there has sometimes been an assumption that nearness in structure to humans is the best estimate of sophistication. However, such estimates should take account of function rather than anatomy alone, because animals vary in the parts of the brain that have complex analytical functions. Although some mammals have high level analysis functions in the cerebral cortex, a comparable high level of analysis occurs in areas of the striatum in birds and in a variety of brain regions in fish and cephalopods. We may also over-emphasise visual analysis, even though other senses have a more primary role in the lives of many mammals, fish and invertebrates. For example, the world of many mammals is much more olfactory than visual, and that of some fish is centred around lateral-line organs that measure localised pressure changes or electro-receptors monitoring changes in patterns in the surrounding electrical field. If we are evaluating extent of awareness in animals or attempting to ensure that their welfare is good, we should take account of the world as they perceive it.

\section{SENTIENCE, AWARENESS AND ANIMAL WELFARE}

Animals vary in the extent to which they are aware of themselves (DeGrazia 1996) and of their interactions with their environment, including their ability to experience pleasurable states such as happiness and aversive states such as pain, fear and grief. This capacity may be referred to as their degree of sentience. A sentient being is one that has some ability to evaluate the actions of others in relation to itself and third parties, to remember some of its own actions and their consequences, to assess risk, to have some feelings, and to have some degree of awareness (Broom 2006).

Human opinion as to which individuals of our own and other species are sentient has generally changed over time in well-educated societies, to encompass first all humans, instead of just a subset of humans, and then: certain mammals that were kept as companions, animals that seemed most similar to humans such as monkeys, the larger mammals, all mammals, all warmblooded animals, and then all vertebrates. Awareness is defined here as a state in which complex brain analysis is used to process sensory stimuli or constructs based on memory (Broom 1998). Its existence can be deduced, albeit with some difficulty, from behaviour in controlled situations. Awareness has been described using 5 headings: unaware, perceptual awareness, cognitive awareness, assessment awareness, and executive awareness (Sommerville \& Broom 1998). In perceptual awareness, a stimulus elicits activity in brain centres but the individual may or may not be capable of modifying the response voluntarily, e.g. scratching to relieve irritation. Examples of cognitive awareness include a mother recognising her offspring and an individual responding to a known competitor, ally, dwelling place or food type. An individual is showing assessment awareness if it is able to assess and deduce the significance of a situation in relation to itself over a 
short time span, for example vertebrate prey responding to a predator recognised as posing an immediate threat but not directly attacking. Executive awareness exists when the individual is able to assess, deduce and plan in relation to long-term intention. In order to have intentions, the individual must have some capability to plan for the future. This requires that information received now can be related to a concept of events that will occur in the future. Executive awareness may involve deductions about choices of action available to that individual (retroduction), the feelings of others, imagination, and the mental construction of elaborate sequences of events.

The complexity of brain organisation is greater for animals that must contend with a varied environment. Such animals have an elaborate motivational system that allows them to think about the impacts of that environment and then take appropriate decisions. Some kinds of feeding methods and predator avoidance demand a great cognitive capacity, but the most demanding thing in life for humans and many other species is to live and organise behaviour effectively in a social group (Humphrey 1976, 1992, Broom 1981, 2003). Animals that live socially are generally more complex in their functioning and in their cognitive capacity than related animals that are not social. When deciding whether animals are sentient, a first step is the analysis of the degree of complexity of living that is possible for the members of the species (D. M. Broom \& K. E. Littin unpubl.). Without a level of brain functioning that makes some degree of awareness possible (Sommerville \& Broom 1998), an animal could not normally be sentient.

Animals are more likely to be considered sentient if they can learn much, learn fast and make few errors once they have learned. Classical conditioning and operant conditioning can occur in animals with relatively simple nervous systems, such as the mollusc Aplysia (Lorenzetti et al. 2006) and a headless locust can learn aversive foot-shock conditioning (Carew \& Sahley 1986). Learning is not, in itself, evidence for awareness but is an indicator that further investigation of cognitive ability might reveal the existence of awareness commensurate with sentience. Comparative studies of learning ability are not easy to conduct because learning situations usually require that an operant be performed, and animals may vary in their physical ability to carry out the operant.

Key issues in any discussion of the welfare of fish and invertebrates are: whether they are aware of what is happening around them, whether they are capable of cognitive processing, and whether they can have feelings such as pain. Awareness in fish is discussed by Chandroo et al. (2004a). We know that some fish must have mental representations of their environment in relation to their ability to navigate (Reese 1989, Rodriguez 1994) and that they have the ability to recognise social companions (Swaney et al. 2001). Fish can avoid, for some months or years, places where they encountered a predator (Czanyi \& Doka 1993) or were caught on a hook (Beukema 1970). Some fish species can learn spatial relationships and form mental maps (Odling-Smee \& Braithwaite 2003), and can use information about sequences of spatial information (Burt de Perera 2004). The parts of the brain used to achieve this are not anatomically the same in fish (Broglio et al. 2003) as in mammals, but the function is very similar. It is clear that the timing of events can be integrated to allow the fish to produce appropriate avoidance responses (Portavella et al. 2004, Yue et al. 2004), and it is difficult to explain the results of these studies without assuming that the fish feel fear. The learning ability demonstrated in a range of studies (Sovrano \& Bizazza 2003) indicates sophisticated cognitive processes that are more complex than associative learning. In recent years, many studies of mammals and birds have indicated that the animals may use different strategies at different times in order to cope with the same problem. When Schjolden et al. (2005) investigated individual variation in the responses of trout to a difficult situation, it was clear that the fish were using coping strategies that involved agonistic behaviour, or physiological responses, or both to deal with the problem.

A feeling is a brain construct involving at least perceptual awareness that is associated with a life-regulating system, is recognisable by the individual when it recurs, and may change behaviour or act as a reinforcer in learning (Broom 1998). The ability to feel pain is generally included amongst the capabilities of sentient animals, and pain is an important cause of poor welfare, but the pain system also includes both simple sensory aspects and complex brain analysis. In humans, nociception is considered by some to be the physiological relay of pain signals: an involuntary, reflex process not involving the conscious parts of the brain. However, it has been proposed that the separation of one part of the pain system from other parts by the use of the term nociception should be discontinued because the system should be considered as a whole (Wall 1992, Broom 2001). Pain leads to aversion, i.e. to behavioural responses involving immediate avoidance and learning to avoid a similar situation or stimulus later. Pain has a sensory component often related to injury, but also requires complex brain functioning of the kind associated with a feeling. Based on the International Association for the Study of Pain definition (Iggo 1984), Kavaliers (1989) suggested that for nonhumans, pain is 'an aversive sensory experience caused by actual or potential injury that elicits protec- 
tive motor and vegetative reactions, results in learned avoidance and may modify species-specific behaviour, including social behaviour'. More simply, Smith \& Boyd (1991) considered pain to be the conscious, emotional experience that, in humans, involves nerve pathways in the cerebrum. Hence, a definition of pain should refer to the sensory and emotional aspects, and the reference to function and consequences is not needed as it may unnecessarily restrict its meaning. Accordingly, Broom (2001) defined pain as an aversive sensation and feeling associated with actual or potential tissue damage.

If pain occurs in an animal, it can cause poor welfare. The degree of awareness in animals that can feel pain will vary but many people consider that the protection of a group of animals is not necessary unless they are capable of feeling pain.

Many kinds of aquatic and terrestrial animals have a pain system involving receptors, neural pathways and analytical centres in the brain. There is also evidence from many animal groups of physiological responses, direct behavioural responses and ability to learn from such experiences so that they are minimised or avoided in future. This suggests the existence of feelings of pain in many species. Feelings, such as pain, fear, and various kinds of pleasure will often be an important part of the biological mechanism for coping with actual or potential damage. Sometimes the response is to avoid whatever is causing the damage. Consequent learning allows the minimising of future damage and, where the pain is chronic, behaviour and physiology can be changed to ameliorate adverse effects. Pain systems have been identified by anatomical and physiological investigation and by studies of behavioural responses, particularly with the assistance of analgesic administration as an experimental probe.

Species differ in their responses to painful stimuli. For example, dogs and humans make much noise but sheep do not, because loud vocalisations may elicit help from social group members in dogs and humans, but just attract more predator attention to an injured sheep. Hence, different responses are adaptive in different species. The feeling of pain may be the same even if the responses are very different. However, even if immediate responses vary, avoidance of the painful stimulus and the effects of learning to avoid such stimuli on subsequent exposure to the stimulus would be observable in fish or invertebrates as well as in mammals and birds. Other feelings such as fear, anxiety, and various forms of pleasure have also been deduced to exist by careful observation and experiment.

The occurrence of pain in fish is debated by Broom (2001), Rose (2002), Jackson (2003), Chandroo et al. (2004a,b) and Braithwaite \& Huntingford (2004). In the rainbow trout Onchorhynchus mykiss, anatomical and electrophysiological investigation of the nociceptors connected to the trigeminal nerve revealed that these fish have 2 types of nociceptor, A-delta and C fibres (Sneddon 2002, Sneddon et al. 2003a). The transmitter, substance-P and the analgesic opioid enkephalins and $\beta$-endorphin, which act as endogenous analgesics in mammals, are present in fish (Rodrigues-Moldes et al. 1993, Zaccone et al. 1994, Balm \& Pottinger 1995), and the behavioural responses of goldfish to analgesics are the same as in rats (Ehrensing et al. 1982). When Sneddon et al. (2003b) administered weak acetic acid solution or bee venom to the mouth of a trout, the fish rested on the substratum, rocked from side to side and rubbed their snouts on solid surfaces. These behaviours, which varied somewhat according to the stimulus, stopped when the analgesic morphine was given.

Fish have a hypothalamic-pituitary-interrenal response that is almost identical to the HPA response of mammals. Stimuli which are disturbing to fish, elicit the production of adrenaline and noradrenaline from the chromaffin tissue (Perry \& Bernier 1999). At the same time, corticotrophin releasing hormone $(\mathrm{CRH})$ is released from the hypothalamus and leads to release of adrenocorticotrophic hormone (ACTH) from the pituitary and this, in turn, is carried by the blood to the interrenal tissue, an analogue of the mammalian adrenal gland where cortisol is produced (Sumpter 1997, Huntingford et al. 2006).

Cephalopods have nociceptors that respond maximally to an injurious stimulus but not to an innocuous stimulus, and increase in sensitivity after tissue has been injured to help the animal avoid further injury. There is also some indication that the nociceptor rate of firing or sensitivity is related to the sensitivity of the tissue that they protect (Mather 2004). Cephalopods can learn to avoid putatively painful stimuli (Young 1991), and have many of the neurotransmitters that are involved in vertebrate pain reception and mediation (Abbott et al. 1995).

Octopuses have been trained to withdraw from or alter their behaviour in response to a conditioned stimulus when this has been previously paired with an electric shock (Robertson et al. 1995). If a vertebrate species is used in such studies, it is usually taken for granted that the learning process has arisen as the result of the animal experiencing pain or discomfort from the electric shock.

Many other invertebrate animals have elements of a pain system (Sherwin 2001). However, references are quoted here for Cephalopoda and Decapoda only. Insects and spiders have not been clearly demonstrated to respond to pain in a way that suggests that they are aware of it. Decapod crustaceans show behavioural, anatomical and physiological indications of 
having a sophisticated pain system. They have nociceptors that supply information to ganglia involved in learning (Sandemann et al. 1992). Avoidance learning to noxious stimuli occurs in crayfish (Kawai et al. 2004) and sand lobsters (Sherwin 2001). Analgesic opioids affecting responses and learning have been reported in shrimps and crabs etc. by Maldonado \& Mirata (1982), Lozda et al. (1988) and Bergamo et al. (1992). As in vertebrates, naloxone inhibits the opioid action (Dyakonova 2001).

The welfare of an animal is 'its state as regards its attempts to cope with its environment' (Broom 1986). As explained below and by Broom (2006) and D. M. Broom \& K. E. Littin (unpubl.), there are many ways in which welfare of sentient animals can be poor. Actually or potentially harmful events might be more readily recognised and receive more attention as a result of the cognitive ability of the animal. For some sentient animals, pain can be especially disturbing on some occasions because the individual concerned uses its sophisticated brain to appreciate that such pain indicates a major risk. However, more sophisticated brain processing will also provide better opportunities for coping with some problems. For example, humans may have means of dealing with pain that fish do not, and may suffer less from pain because they are able to rationalise that it will not last for long. Therefore, in some circumstances, humans who experience a particular pain might suffer more than fish, whilst in other circumstances a certain degree of pain may cause worse welfare in fish than in humans (Broom 2001, 2006). These arguments will also be valid for other causes of poor welfare. Fear is likely to be much greater in its impact if the context and risk cannot be analysed. In addition, more complex brains should allow more possibilities for pleasure, and this contributes greatly to good welfare.

\section{CAPABILITIES OF AQUATIC ANIMALS AND THE NEED FOR PROTECTION}

The case for protecting cephalopods has been presented by Mather (1995), Mather \& Anderson (2007, this issue) and by D. M. Broom \& K. E. Littin (unpubl.). Some of the evidence has been described by Nixon \& Young (2003) and EFSA Scientific Panel on Animal Health and Welfare (2005). The general physiological functioning of cephalopods is impressive: for example, their food conversion efficiency is significantly greater than that of mammals (Boyle 1987). They have an adrenal system and release adrenal hormones in response to situations that would elicit pain and distress in humans (Broom 1998, 2001, Stefano et al. 1998, 2002). They secrete noradrenaline and dopa- mine in response to disturbing events (e.g. air exposure, food withdrawal). Their perceptual ability is substantial, as is their brain complexity. Experience affects their behaviour development and they have sophisticated learning ability with long- and shortterm memory. Cephalopods can modify previous learning, learn mazes, use flexible route-planning, have individual differences, show simultaneous different responses to individuals on the 2 sides of the body, use tools, and carry out behaviour that leads to deception. Their ability to change colour seems to be associated with an unpleasant emotion, e.g. after fighting or handling. Social cuttlefish and squid show specific colour pattern changes in situations that appear to involve risk of attack and hence fear in the animals (Moynihan 1985). Cephalopods show colour change and behavioural response to crowding and danger (Budelmann 1998, Boal et al. 1999, Messenger 2001). Decapod crustaceans exhibit complex learning ability and there is good evidence for memory lasting several days (Tomsic et al. 1996, Feld et al. 2005, Gherardi \& Atema 2005).

The general conclusion from the evidence presented on the functioning of fish, cephalopods and decapod crustaceans is that we should be concerned about their welfare and that there should be some protection of these animals so that human actions do not cause their welfare to be poor.

\section{WELFARE ISSUES IN THE FISH-FARMING INDUSTRY}

There has been a limited amount of research on the welfare of farmed fish (Turnbull 2006). Almost nothing is published on the welfare of other farmed aquatic animals. In light of the conclusions above, investigations of the welfare of farmed decapods would seem to be necessary. For example, how is their welfare affected by crowding, handling, salinity change, adverse temperatures, and food shortage etc.?

\section{Terminology}

A point that should be considered within the fishfarming industry is the extent to which attitudes to fish welfare are affected by the terminology that is used. In English, there has been a tendency to use plant terms when referring to farmed fish or fish taken from the sea. A cage full of salmon is sometimes called a crop, and the process of slaughter is sometimes called harvesting. Farmers refer to 'growing the fish', like 'growing wheat', but animals are not the same as plants. It is the fish that grow and the farmer who feeds and man- 
ages them. Such terms make the fish seem less like individual animals, and encourage farm staff to view them as objects rather than sentient beings and perhaps to treat them badly. Hence the terms 'crop' and 'harvest' and 'growing the fish' are inappropriate and should not be used.

The following is a list of problems in the fish-farming industry, some of which are also relevant to pet fish. Those that might be considered to be most important are mentioned first.

\section{Stocking density}

Some fish live in shoals and prefer close schooling so that the nearest neighbour is a short distance away, e.g. arctic charr Salvelinus alpinus (Jergensen et al. 1993). In other species whose individuals are forced to endure a higher density than they would choose, high stocking densities on fish farms, or in captivity for other purposes, cause poor welfare (e.g. Ewing \& Ewing 1995 for trout and salmon; Vazzana et al. 2002 for sea-bass; Montero et al. 1999 for seabream). When high stocking density was combined with insufficient water flow (Ellis et al. 2002) or with too much disturbance (Turnbull et al. 2005), welfare was worse than with any single adverse factor, so the effects of such problems on welfare is additive or multiplicative.

Farmed salmon and trout kept at high stocking densities usually have damaged fins. It is likely that much of this damage is caused by either fin-chewing by other fish or as a result of contact with other fish, rather than by contact with the cage or tank. Fin damage in trout was higher when there was food deprivation (Winfree et al. 1998).

Other species of fish that are largely herbivorous may be less likely to show fin-chewing behaviour, but many species have chewed fins at high stocking densities. The stocking density should allow fish to show most normal behaviour and avoid having to show abnormal behaviour, with minimal pain, stress and fear.

\section{Feeding methods}

Food distributed in such a way that each individual can get sufficient food is a requirement for the keeping of farm animals. Farmed fish are usually subject to great competition when food is provided for them. Observations of salmon in cages during food provision show that the largest and fastest fish get a disproportionate amount of food, and a high proportion of smaller individuals that are less able to compete are found at the edges of the cage. Observations during diving showed that smaller animals were at the cage edge all the way down to the bottom of the cage, 15 to $20 \mathrm{~m}$ below the surface (D. M. Broom pers. obs.). If food was made available on demand for salmon, they swam more slowly and exhibited less fighting behaviour than when it was supplied by broadcasting, i.e. in a way that led to much competition.

Food should be distributed evenly and widely so that it reaches the maximum number of fish, ideally every individual. Better systems for the provision of adequate amounts of food to all fish should be developed.

\section{Catching and killing methods}

In European countries, and indeed in most countries in the world, farm animals are required to be killed in a humane way that includes prior stunning. This should be applied to fish also. It is unacceptable for fish to die from asphyxiation in air because welfare will be very poor at this time. Cooling on ice before death prolongs the period of poor welfare (Robb et al. 2000). The percussive method is used for salmon, using either a specially designed club or a mechanical stunning device. The blow should be of sufficient force for the fish to be immediately rendered unconscious and for it to remain so until dead.

A satisfactory method of slaughtering smaller fish such as trout en masse, which renders them insensible instantaneously and until death supervenes, is required. The widely used method of leaving the animals to suffocate in air is not acceptable. Electrical stunning seems to be the best available method of doing this (Lines et al. 2003). Staff employed in slaughter of fish should have the knowledge and skill to perform the task humanely and efficiently for the method employed.

On some fish farms, instead of catching the fish in the water in the most rapid and least disturbing way, people are allowed to come to the farm and catch the fish with a hook and line. Hooking and handling fish for release increases scale damage, making the fish more vulnerable to infection (Broadhurst \& Barker 2000). Injury and mortality following the hooking of fish is common, especially where the hook penetrates deep into the tissues (Muonehke \& Childress 1994), and the mortality increase is clear in live-release tournaments (Suski et al. 2005). The actual process of capture on a hook leads to increased heart rate, cortisol production, and subsequent avoidance of the situation (Verheijen \& Buwalda 1988, Pottinger 1998, Cooke \& Philipp 2004). Later effects of capture and a period in air before being returned to water include suppression of immune system function, suppression of oestradiol 
levels, reduced reproductive ability, and severe metabolic effects (Pickering \& Pottinger 1989, Melotti et al. 1992, Ferguson et al. 1993, Pankhurst \& Dedual 1994). A period in a keep net also leads to adrenal responses: sometimes prolonged, but sometimes rather brief (Pottinger 1998).

This clear evidence of poor welfare when fish are hooked, removed from water, handled and held in a keep net should be taken into account by those who fish for their own entertainment. Legislation in many countries now makes it illegal to impose poor welfare on fish used in experiments and farmed fish, unless the practice can be justified. The capture of fish in open-water fishing is justified for many people by human food requirements, but the methods used cause poor welfare to a great extent and welfare standards are thus needed to improve such practices.

\section{Environmental quality enrichment}

Fish are kept with conspecifics, so they are not deprived of social contact. However, in other respects their environment is rather barren. More information is required on whether fish welfare can be improved by environmentally enriching stimuli and on how to provide for all of the needs of fish, including any need for varied stimulation.

\section{Disease and parasitism}

Pathogens and parasites generally cause poor welfare in fish. Hence, it is important to manage fish so as to minimise disease. A key aspect of this is to have good methods of inspecting fish to recognise those that are diseased, distressed or dead. As a result of efforts to reduce or avoid the widespread use of antibiotics in fish farming, vaccination is used frequently. However, because of the handling involved and the use of irritant adjuvants, welfare can be very poor for short periods because of immediate effects of handling, and poor for long periods because of increased injury and pathology (Sørum \& Damsgaard 2003).

\section{Handling, grading and transport}

Fish show a maximal emergency adrenal response when removed from water. Methods of movement of fish that do not require removal from water are preferable on grounds of fish welfare. However, any kind of manual handling, many aspects of the grading procedure and some aspects of transport are very stressful to fish, and usually increase susceptibility to disease (Strangeland et al. 1996, Pickering 1998).

Fish populations should not be graded more often than is absolutely necessary because grading, with its associated crowding, leads to prolonged increases in plasma cortisol concentrations and most kinds of grading are likely to be stressful for fish.

During the stripping and milking processes, the more times a fish is handled and exposed to sedation, the greater the skin injury and stress. If effective anaesthetics are used and maintained at an appropriate concentration throughout sedation and anaesthesia, fish welfare is much improved.

\section{Predators and farmed fish}

When fish are farmed, it is often necessary for measures to be to taken to protect the fish from predators because mortality can be high (Carss 1993), and they show strong emergency adrenal responses and also suppression of feeding when predators are present (Metcalfe et al. 1987). Many of the predators are species that the general public hold in high regard, for example seals, otters, herons, kingfishers or gannets. Hence, it is necessary for there to be anti-predator measures that minimise poor welfare of the predators and do not endanger predator populations. The killing of predators should be a last resort.

\section{SUMMARY}

(1) Our knowledge of the functioning of the brain and nervous system and of animal welfare has advanced rapidly in recent years. Some of this new knowledge concerns aquatic animals.

(2) Concern for animal welfare is increasing rapidly and is a significant factor affecting whether or not animal products are bought. If a product is perceived to be associated with bad effects on human health, animal welfare or the environment, sales can slump dramatically. The fish-farming industry cannot afford to ignore fish welfare when bad publicity about it could affect sales greatly.

(3) There is evidence from some species of fish, cephalopods and decapod crustaceans of substantial perceptual ability, pain and adrenal systems, emotional responses, long- and short-term memory, complex cognition, individual differences, deception, tool use, and social learning. The case for protecting these animals would appear to be substantial.

Acknowledgements. I thank K. E. Littin, J. A. Mather, C. M. Sherwin and R. Williamson for helpful discussions. 


\section{LITERATURE CITED}

Abbott NJ, Williamson R, Maddock L (1995) Cephalopod neurobiology - neuroscience studies in squid, octopus, and cuttlefish. Oxford University Press, Oxford

Balm PHM, Pottinger TG (1995) Corticotrope and melanotrope POMC-derived peptides in relation to inter-renal function during stress in rainbow trout (Oncorhynchus mykiss). Gen Comp Endocrinol 98:279-288

Barton RA, Dunbar RIM (1997) Evolution of the social brain. In: Whiten A, Byrne RW (eds) Machiavellian intelligence II. Cambridge University Press, Cambridge, p 240-263

Bennett RM (1994) Valuing farm animal welfare. University of Reading, Reading

Bergamo P, Maldonado H, Miralto A (1992) Opiate effect on the threat display in the crab Carcinus mediterraneus. Pharmacol Biochem Behav 42:323-326

Beukema JJ (1970) Angling experiments with carp: decreased catchability through one trial learning. Neth J Zool 20:81-92

Boal GJ, Hylton RA, Gonzalez SA, Hanlon RT (1999) Effects of crowding on the social behavior of cuttlefish (Sepia officinalis). Contemp Top Lab Anim Sci 38:49-55

Boyle PR (1987) Cephalopod life cycles, Vol 2. Academic Press, London

Braithwaite VA, Huntingford FA (2004) Fish and welfare: do fish have the capacity for pain perception and suffering? Anim Welf 13:587-592

Broadhurst MK, Barker DT (2000) Effects of capture by hook and line on plasma cortisol, scale loss and survival in juvenile mulloway (Agrysomus hololepidotus). Arch Fish Mar Res 48:1-10

Broglio C, Rodriguez F, Salas C (2003) Spatial cognition and its neural basis in teleost fishes. Fish Fish 4:247-255

Broom DM (1981) Biology of behaviour. Cambridge University Press, Cambridge

Broom DM (1986) Indicators of poor welfare. Brit Vet J 142: 524-526

Broom DM (1994) The valuation of animal welfare in human society. In: Bennett RM (ed) Valuing farm animal welfare. University of Reading, Reading, p 1-7

Broom DM (1998) Welfare, stress and the evolution of feelings. Adv Study Behav 27:371-403

Broom DM (1999) Fish welfare and the public perception of farmed fish. Proc Aquavision :1-6

Broom DM (2001) Evolution of pain. R Soc Med Int Congr Symp Ser 246:17-25

Broom DM (2003) The evolution of morality and religion. Cambridge University Press, Cambridge

Broom DM (2006) The evolution of morality. Appl Anim Behav Sci 100:20-28

Broom DM, Johnson KG (2000) Stress and animal welfare. Kluwer Academic, Dordrecht

Broom DM, Zanella AJ (2004) Brain measures which tell us about animal welfare. Anim Welf 13:S41-S45

Budelmann BU (1998) Autophagy in octopus. S Afr J Mar Sci 20:101-108

Burt de Perera T (2004) Fish can encode order in their spacial map. Proc R Soc Lond B 271:2131-2134

Carew TJ, Sahley CL (1986) Invertebrate learning and memory: from behavior to molecules. Annu Rev Neurosci 9: 435-487

Carss DN (1993) Cormorants Phalacrocorax carbo at cage fish farms in Argyll, western Scotland. Seabird 15:38-44

Chandroo KP, Duncan IJH, Moccia RD (2004a) Can fish suffer? Perspectives on sentience, pain, fear and stress. Appl Anim Behav Sci 86:225-250
Chandroo KP, Yue S, Moccia RD (2004b) An evaluation of current perspectives on consciousness and pain in fishes. Fish Fish 5:281-295

Cooke SJ, Philipp DP (2004) Behavior and mortality of caught-and-release bonefish (Albula spp.) in Bahamian waters with implications for a sustainable fishery. Biol Conserv 118:599-607

Czanyi V, Doka A (1993) Learning interactions between prey and predator fish. Mar Behav Physiol 23:63-78

DeGrazia D (1996) Taking animals seriously: mental life and moral status. Cambridge University Press, New York

Dyakonova VE (2001) Role of opioid peptides in behavior of invertebrates. J Evol Biochem Physiol 37:335-347

EFSA (European Food Safety Authority) Scientific Panel on Animal Health and Welfare (2005) Aspects of the biology and welfare of animals used for experimental and other scientific purposes. EFSA J 292:1-136

Ehrensing RH, Michell GF, Kastin AJ (1982) Similar antagonism of morphine analgesia by MIF-1 and naloxone in Carassius auratus. Pharmacol Biochem Behav 17:757-761

Ellis T, North B, Scott AP, Bromage NR, Porter M, Gadd D (2002) The relationships between density and welfare in farmed rainbow trout. J Fish Biol 61:493-531

Ewing RD, Ewing SK (1995) Review of the effects of rearing density on the survival to adulthood for Pacific salmon. Prog Fish-Cult 57:1-25

Feld M, Dimant B, Delorenzi A, Coso O, Romano A (2005) Phosphorylation of extra-nuclear ERK/MAPK is required for long-term memory consolidation in the crab Chasmagnathus. Behav Brain Res 158:251-261

Ferguson RA, Kieffer JD, Tuffs BL (1993) The effects of body size on the acid-base and metabolite status in the white muscle of rainbow trout before and after exhaustive exercise. J Exp Biol 180:195-207

Gherardi F, Atema J (2005) Memory of social partners in hermit crab dominance. Ethology 111:271-285

Hemmer H (1983) Domestikation: Verarmung der Merkwelt. Viewig, Braunschweig

Humphrey NK (1976) The social function of intellect. In: Bateson PPG, Hinde RE (eds) Growing points in ethology. Cambridge University Press, Cambridge, p 303-317

Humphrey NK (1992) A history of mind. Chatto \& Windus, London

Huntingford FA, Adams C, Braithwaite VA, Kadri S, Pottinger TG, Dandoe P, Turnbull JF (2006) Current issues in fish welfare. J Fish Biol 68:332-372

Iggo A (1984) Pain in animals. Universities Federation for Animal Welfare, Potters Bar

Jackson C (2003) Laboratory fish: impacts of pain and stress on well-being. Contemp Top Lab Anim Sci 42:62-73

Jergensen EH, Christiansen JS, Jobling M (1993) Effects of stocking density on food intake, growth performance and oxygen consumption in Arctic charr (Salvelinus alpinus). Aquaculture 110:191-204

Jerison HJ (1973) Evolution of brain and intelligence. Academic Press, New York

Kavaliers M (1989) Evolutionary aspects of the neuromodulation of nociceptive behaviors. Am Zool 29: 1345-1353

Kawai N, Kono R, Sugimoto S (2004) Avoidance learning in the crayfish (Procambarus clarkii) depends on the predatory imminence of the unconditioned stimulus: a behavior systems approach to learning in invertebrates. Behav Brain Res 150:229-237

Lines JA, Rob DH, Kestin SC, Crook SC, Benson T (2003) Electric stunning: a humane slaughter method for trout. Aquacult Eng 28:141-154 
Lorenzetti FD, Mozzachiodi R, Baxter DQ, Byrne JH (2006) Classical and operant conditioning differentially modify the intrinsic properties of an identified neuron. Nature Neurosci 9:17-19

Lozda M, Romanao A, Maldonado H (1988) Effect of morphine and naloxone on a defensive response of the crab, Chasmagnathus granulatus. Pharmacol Biochem Behav 30:635-640

Maldonado H, Miralto A (1982) Effect of morphine and naloxone on a defensive response of the mantis shrimp (Squilla mantis). J Comp Physiol A 147:455-459

Mather JA (1995) Cognition in cephalopods. Adv Study Behav 24:316-353

Mather JA (2004) Cephalopod skin displays: from concealment to communication. In: Oller K, Greibel U (eds) Evolution of communication systems. MIT Press, Cambridge, MA, p 193-213

Mather JA, Anderson RC (2007) Ethics and invertebrates: a cephalopod perspective. Dis Aquat Org 75:119-129

Melotti P, Roncarati A, Garella E, Carnevali O, Mosconi G, Polzonetti-Magni A (1992) Effects of handling and capture stress on plasma glucose, cortisol and androgen levels in brown trout (Salmo trutta morpha fario). J Appl Ichthyol 8:243-239

Messenger JB (2001) Cephalopod chromatophores: neurobiology and natural history. Biol Rev 76:473-528

Metcalfe NB, Huntingford FA, Thorpe JE (1987) The influence of predation risk on the feeding motivation and foraging strategy of juvenile Atlantic salmon. Anim Behav 35:901-911

Montero D, Izquierdo MS, Tort L, Robaina L, Vergara JM (1999) High stocking density produces crowding stress altering some physiological and biochemical parameters in gilthead sea-bream, Sparua aurata, juveniles. Fish Physiol Biochem 20:53-50

Moynihan M (1985) Communication and non-communication by cephalopods. Indiana Press, Bloomington, IN

Muonehke MI, Childless WM (1994) Hooking mortality: a review for recreational fisheries. Rev Fish Sci 2:123-156

Nixon M, Young JZ (2003) The brains and lives of cephalopods. Oxford University Press, Oxford

Odling-Smee L, Braithwaite VA (2003) The role of learning in fish orientation. Fish Fish 4:235-246

Pankhurst NW, Dedual M (1994) Effect of capture and recovery on on plasma levels of cortisol, lactate and gonadal steroids in a natural population of rainbow trout. J Fish Biol 45:1013-1025

Perry S, Bernier NJ (1999) The acute hormonal adrenergic stress response in fish: facts and fiction. Aquaculture 177: 285-295

Pickering AD (1998) Stress responses in farmed fish. In: Black KD, Pickering AD (eds) Biology of farmed fish. Sheffield Academic Press, Sheffield, p 222-255

Pickering AD, Pottinger TG (1989) Stress response and disease resistance in salmonid fish: effects of chronic elevation of plasma cortisol. Fish Physiol Biochem 7:253-258

Portavella M, Torres B, Salas C (2004) Avoidance response in goldfish: emotional and temporal involvement of medial and lateral telencephatic pallium. J Neurosci 24: 2342-2335

Pottinger TG (1998) Changes in blood cortisol, glucose and lactate in carp retained in anglers' keep nets. J Fish Biol 53:728-742

Reese ES (1989) Orientation behaviour of butterfly fishes (family Chaetodontidae) on coral reefs - spatial learning of route specific landmarks and cognitive maps. Environ Biol Fish 25:79-86
Robb D, Kestin S, Lines J (2000) Progress with humane slaughter. Fish Farmer Nov/Dec:41

Robertson JD, Bonaventura J, Kohm A (1995) Nitric-oxide synthetase inhibition blocks octopus touch learning without producing sensor or motor dysfunction. Proc R Soc Lond B 261:167-172

Rodriguez F, Duran E, Vargas JP, Torres B, Salas C (1994) Performance of goldfish trained in allocentric and egocentric maze procedures suggests the presence of a cognitive mapping system in fishes. Anim Learn Behav 22: 409-420

Rodriguez-Moldes I, Manso MJ, Becerra M, Molist $\mathrm{P}$, Anadon R (1993) Distribution of substance P-like immunoreactivity in the brain of the elasmobranch Scyliorhinus canicula. J Comp Neurol 333:228-244

Rose JD (2002) The neurobehavioural nature of fishes and the question of awareness and pain. Rev Fish Sci 10:1-38

Sandeman D, Sandeman R, Derby C, Schmidt M (1992) Morphology of the brain of crayfish, crabs, and spiny lobsters: a common nomenclature for homologous structures. Biol Bull (Woods Hole) 183:304-326

Schjolden J, Stoskhus S, Winberg S (2005) Does individual variation in stress responses and agonistic behavior reflect divergent stress coping strategies in juvenile rainbow trout? Physiol Biochem Zool 78:715-723

Sherwin CM (2001) Can invertebrates suffer? Or, how robust is argument-by-analogy? Anim Welf 10(Suppl): S103-S118

Smith KA, Boyd KM (1991) Lives in the balance: the ethics of using animals in biomedical research. Oxford University Press, Oxford

Sneddon LU (2002) Anatomical and electrophysiological analysis of the trigeminal nerve in a teleost fish, Oncorhynchus mykiss. Neurosci Lett 319:167-171

Sneddon LU, Braithwaite VA, Gentle MJ (2003a) Do fish have nociceptors? Evidence for the evolution of a vertebrate sensory system. Proc R Soc Lond B 270:1115-1121

Sneddon LU, Braithwaite VA, Gentle MJ (2003b) Novel object test: examining nociception and fear in the rainbow trout. J Pain 4:431-440

Sommerville BA, Broom DM (1998) Olfactory awareness. Appl Anim Behav Sci 57:269-286

Sørum U, Damsgaard B (2003) Effects of anaesthetization and vaccination on feed intake and growth of Atlantic salmon (Salmo salar L.). Aquaculture 232:333-341

Sovrano VA, Bisazza A (2003) Modularity as a fish (Zenotoca eisen) views it: conjoining and nongeometric information for special reorientations. J Exp Psychol 29:199-210

Stefano GB, Salzet B, Fricchione GL (1998) Enkelytin and opioid peptide association in invertebrates and vertebrates: immune activation and pain. Immunol Today 19: $265-268$

Stefano GB, Cadet P, Zhu W, Rialas CM and 7 others (2002) The blueprint for stress can be found in invertebrates Neuroendocrinol Lett 23:85-93

Strangeland K, Hoie S, Taksdal T (1996) Experimental induction of infectious pancreatic necrosis in Atlantic salmon (Salmo salar L.) post-smolts. J Fish Dis 19:323-327

Sumpter JP (1997) The endocrinology of stress. In: Iwama GK, Pickering AD, Sumpter JP, Schreck CB (eds) Fish stress and health in aquaculture. Cambridge University Press, Cambridge, p 95-118

Suski CD, Cooke SJ, Killin SJ, Wahl DH, Phipp DP (2005) Behaviour of walleye, Sander vitreus, and largemouth bass, Micropterus salmoides, exposure to different wave intensities and boat operating conditions during livewell confinement. Fish Manage Ecol 12:19-26 
Swaney W, Kendal J, Capon H, Brown C, Laland KN (2001) Familiarity facilitates social learning of foraging behaviour in the guppy. Anim Behav 62:591-598

Tomsic D, Dimant B, Maldonado H (1996) Age-related deficits of long-term memory in the crab Chasmagnathus. J Comp Physiol A 178:139-146

Turnbull JF (2006) Current issues in fish welfare. J Fish Biol 68:332-372

Turnbull JF, Bell A, Adams CE, Bron J, Huntingford FA (2005) Stocking density and welfare of cage farmed Atlantic salmon: application of a multivariate analysis. Aquaculture 243:121-132

Vazzana M, Cammerata M, Cooper EL, Parrinello N (2002) Confinement stress in sea bass (Dicentrarchus labrax) depresses peritoneal leukocyte cytotoxicity. Aquaculture 210:231-243

Verheijen FJ, Buwalda RJA (1988) Do pain and fear make a

Editorial responsibility: Anne Berit Skiftesvik, Storebø, Norway hooked carp in play suffer? CIP-Gegevens, Utrecht

Wall PD (1992) Defining 'pain in animals'. In: Short CE, van Poznak A (eds) Animal pain. Churchill Livingstone, New York, p 63-79

Winfree RA, Kindschi GA, Shaw HT (1998) Elevated water temperature, crowding and food deprivation accelerate fin erosion in juvenile steelhead. Prog Fish-Cult 60:192-199

Young JZ (1991) Computation in the learning-system of cephalopods. Biol Bull (Woods Hole) 180:200-208

Yue S, Moccia RD, Duncan IJH (2004) Investigating fear in domestic rainbow trout, Oncorhynchus mykiss, using an avoidance learning task. Appl Anim Behav Sci 87: 343-354

Zaccone G, Fasula S, Ainis L (1994) Distribution patterns of the paraneuronal endocrine cells in the skin, gills and the airways of fishes determined by immunohistochemical and histological methods. Histochem J 26:609-629

Submitted: January 21, 2007; Accepted: February 26, 2007 Proofs received from author(s): April 20, 2007 